\title{
Variations of digestibility of a hay diet between Charolais cows
}

\author{
J Agabriel, M Petit, JM Giraud \\ INRA, Laboratoire Adaptation des Herbivores aux Milieux, Theix, \\ 63122, Saint-Genès-Champanelle, France
}

The range of variations in organic matter digestibility $(O M D)$ can reach $6-7$ points $(10-15 \%)$ between different Charolais cows fed a hay diet (Agabriel et al, 1992).

A diet composed on a DM basis of $49 \%$ cocksfoot hay $(C P=140 \mathrm{~g} / \mathrm{kgDM}), 46 \%$ timothy hay $(\mathrm{CP}=105 \mathrm{~g} / \mathrm{kgDM}$ ), and $5 \%$ concentrate (soybean meal and minerals) was fed on a restricted basis to Charolais cows $(1.4 \mathrm{~kg} / 100 \mathrm{~kg}$ live weight). OMD of the diet was first measured by total faecal collection over a $10 \mathrm{~d}$ pre-experimental period on 18 dry and pregnant cows (7th month), and averaged $55.0 \pm 1.6 \%$. Five of these cows were selected for further measurements: 3 cows with high OMD $(56.0-58.9 \%$, group $\mathrm{H})$, and 2 cows with low OMD (51.8 and $54.4 \%$, group L). Cows were similar in age and weight, and were healthy (good teeth and no internal parasites). OMD was then measured over 9 weeks with 5 days collection per week (fig 1). All cows calved during these periods but there is no measurement in lactation for $1 \mathrm{cow}$. Repeatability of ranking order of cows for digestibility was first tested between weeks for 5 cows, and then was tested between physiological stages for 4 cows.

Differences in average OMD between $\mathrm{H}$ and $L$ groups persisted over the 9 weeks and varied between 0.7 and $10.0 \%$. Differences between the 2 individuals registered as extreme during the pre-experimental period, varied between 3.0 and $15.4 \%$, but the ranking order of OMD was not always the same for all weeks because of variations in physiological stage between cows. When tested at the same stage, the ranking order was quite steady in lactation and significantly similar with the pre-experimental one $(p \leq 0.05)$.

$\mathrm{OMD}$ of $\mathrm{H}$-cows decreased before calving $(-3.0$ points), then reached its initial level in lactation (+3.8 points). By contrast, the OMD of $L$ cows did not change during the experiment. There was no difference in average OMD between $\mathrm{H}$ and $L$ cows in the 2 weeks before calving, perhaps because $\mathrm{H}$ cows usually have a slower digestive transit and are therefore more sensitive to the acceleration of transit resulting from metabolic change and foetal volume in late pregnancy. The $\mathrm{H}$-cows received $3 \%$ more digestible energy for the period of 9 weeks. It was also observed that the body condition score for $\mathrm{H}$ cows during the wintering period dropped less: -0.5 vs -1.0 points.

Comprehensive analysis of the performance of beef cows should take into account these variations in digestive capacity, as well as the possibility of other compensations; fast eaters and ruminators have indeed been observed to have the highest intake but the lowest digestibility (Deswysen et al, 1984).

Agabriel J, Giraud JM, Petit M, Mauchamp C (1992) Ann Zootech 41, 63-64

Deswysen AC, Ellis WC, Pond KR (1984) In: Techniques in Particle-Size Analysis of Feed and Digesta in Ruminants (PM Kennedy, ed) p 172

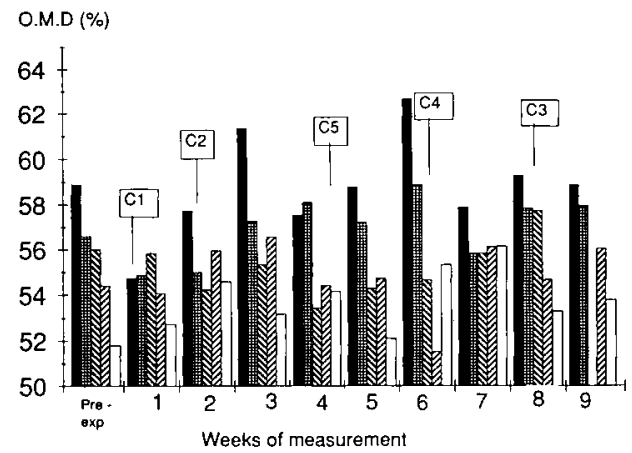

Fig 1. OMD in 5 Charolais cows. cow 1; 四 cow 2; $\$$ cow $3 ; \square \operatorname{cow} 4 ; \square \operatorname{cow} 5$. Cn: week of calving for cow $n$. 